\title{
CORONAVIRUS
}

\section{Too slow and fundamentally flawed: why test and trace is a weak and inequitable defence against covid-19}

\begin{abstract}
The government's long awaited programme is missing a vital aspect of successful contact tracing, public health experts warn, as well as being beset by delays-and it may widen health inequalities. Richard Vize reports
\end{abstract}

\section{Richard Vize journalist}

“I don't believe the virus is under control, and I don't believe that the system of surveillance we have at the present time is sufficient," says Gabriel Scally, former regional public health director and a member of the Independent SAGE group of scientific advisers.

As lockdown restrictions are eased and businesses reopen, he is one of several public health experts worried that England's ability to contain outbreaks of covid-19 is seriously compromised by weaknesses in the planning and operation of the government's much anticipated "test and trace" programme.

Launched on 28 May, test and trace is now at the front line of efforts to prevent further outbreaks. But new infections are still high (an estimated 39 ooo a week in private households in England from 26 April to 30 May 2020, in survey data released by the Office for National Statistics on $5 \mathrm{June}^{2}$ ), testing procedures are slow, and the tracing system is flawed, public health experts tell The BMJ. They also raise concerns about how test and trace could widen health inequalities in populations most affected by the pandemic.

Scally says, "I think the situation is extraordinarily dangerous, and I don't see any sign of the systematic, thorough, well resourced, and expert approach that is needed."

\section{Delays at every stage}

One of the biggest challenges with test and trace is that delays inevitably hamper every stage: a symptomatic person organising and then receiving a test; the test reaching a laboratory and the laboratory analysing the sample; the test results getting to the contact, tracers, and councils; and follow-up action being taken (box 1).

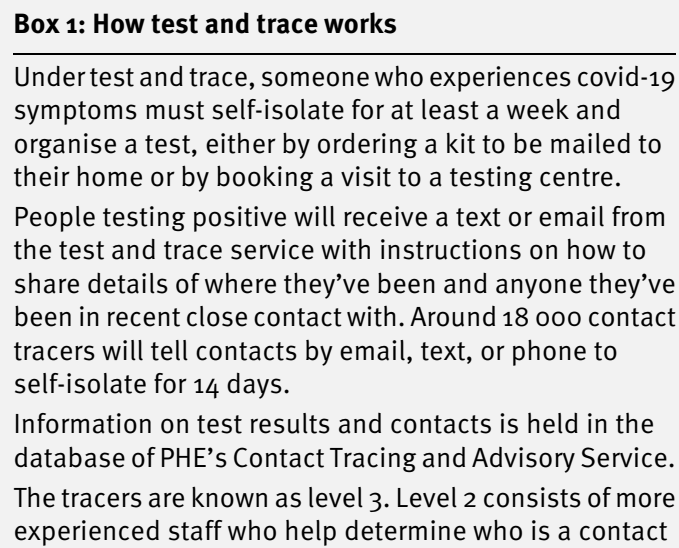
symptoms must self-isolate for at least a week and organise a test, either by ordering a kit to be mailed to their home or by booking a visit to a testing centre. People testing positive will receive a text or email from the test and trace service with instructions on how to share details of where they've been and anyone they've been in recent close contact with. Around 18 ooo contact tracers will tell contacts by email, text, or phone to self-isolate for 14 days.

Information on test results and contacts is held in the database of PHE's Contact Tracing and Advisory Service. The tracers are known as level 3. Level 2 consists of more experienced staff who help determine who is a contact

and what action is required. Above them, at level 1 , are the health protection experts in the PHE regional teams, whose numbers are being increased. They handle the most important cases, such as major outbreaks.

At least daily, PHE updates local authorities on the cases being handled by level 1 that require their involvement, such as an outbreak in a school.

Around three quarters of covid-19 swabs are analysed by the private sector led Lighthouse Labs set up in response to the pandemic, in Milton Keynes, Cheshire, and Glasgow. This includes home testing swabs sent in the post and samples taken at drive-in centres. Public Health England (PHE) and NHS hospital labs mainly handle swabs from patients and health and care workers.

NHS labs have well established logistics to collect samples from places such as care homes and to get them processed quickly, but the privately run Lighthouse Labs use complicated supply chains involving Amazon, Boots, and Royal Mail ${ }^{3}$ to transport samples over long distances.

Allan Wilson is president of the Institute of Biomedical Science, whose members include the scientists running the NHS pathology labs. He says, "We've always argued that the testing would be better done locally because the infrastructure exists already, so why invent another route? The government decided early on that their preference was to develop separate labs. I think it was a political rather than a clinical decision.”

Securing enough supplies to analyse the samples also remains a struggle. Labs analyse samples for covid-19 using precision built modules consisting of reagents, pipette tips, plastic tubes, and probes to detect viral RNA, which are plugged into robotic testing platforms built by companies such as Roche. But, like a printer cartridge, you need the right module for a particular platform. With little manufacturing capacity for these modules, the UK depends on overseas supplies.

Testing capacity is gradually building up as more manufacturers begin producing modules for their own platforms and as other platforms are imported with modules already available. (See box 2.) 


\section{Box 2: What is the Joint Biosecurity Centre?}

A striking feature of the government's pandemic response has been setting up major infrastructure from scratch, including the Nightingale hospitals and the privately operated Lighthouse Labs and testing centres. The latest example is the Joint Biosecurity Centre.

The Institute for Government ${ }^{9}$ says that the Joint Biosecurity Centre will report to the Cabinet Office and will have two main jobs: providing independent, real time analysis locally and nationally about infection outbreaks; and advising the government on how to respond to infection spikes, such as by closing schools or workplaces in a particular area or imposing restrictions on an entire town or region.

The government has given some confused signals on the centre's state of readiness, with Matt Hancock admitting at the Downing Street briefing on 1 June that it "still formally needs to come into existence." ${ }^{10}$

It's not clear how it relates to PHE, which is the repository for pandemic health data. One public health expert speculated unattributably that the centre could augment this disease data with information to identify local outbreaks, such as internet search terms and social media activity, adding, "There is a role for new data sources to do that kind of work, so it makes sense."

\section{Testing times}

The UK prime minister, Boris Johnson, has promised that test results-except those from samples returned by post-will be turned around in 24 hours by the end of June, ${ }^{4}$ but anecdotal evidence suggests that two or three days is currently more typical.

At the health and social care select committee on 3 June, Dido Harding, head of the test and trace programme, was unable to give data on what proportion of tests were turned around within 24 hours or what proportion of contacts of infected people had been contacted within 24 hours and asked to self-isolate. However, she said that over $90 \%$ of people waiting for test results had received them within 48 hours.

The committee chair, Jeremy Hunt, warned that a lack of data could "destroy confidence" in test and trace. He made clear his expectation that the total time from a person being tested to receiving a positive test, their contacts being submitted, and those contacts being asked to self-isolate should be only 48 hours. 5

Jeanelle de Gruchy, director of population health at Tameside Council and president of the Association of Directors of Public Health, says, "The system is currently struggling to get test results back to where they are needed, and we absolutely need to improve it. We are feeding back where it's not working."

\section{Local problem solving}

While this problem continues to dog the national testing programme, the Francis Crick Institute near London's St Pancras Station is already meeting the 24 hour target for the 1000 daily tests it carries out for University College London Hospitals and eight other north London hospitals, as well as care homes and ambulance crews.

Paul Nurse, the institute's Nobel prize winning director, says that the key is being local. He explains, "We're connected, and we solve problems locally. You've got to have the ability to solve problems which happen all the time, such as workflow.

"If you're in Milton Keynes receiving material from Sutton Coldfield or somewhere, that's a much more difficult problem to solve than when you're sitting just across the road and everybody knows each other. It's amazing how many times people are picking up the phone, and it just keeps it all working."

He believes that establishing the massive Lighthouse Labs wasn't properly thought through. "They haven't focused on turnaround time, and we know it's quite a few days, which is going to be very difficult in making tracing work," says Nurse. "We could have had 30 labs like the Crick around the country for a fraction of the cost, and then the big labs could have learnt from those."

However, de Gruchy is optimistic that the turnaround times for testing will be resolved, saying, "Our expectation is that these would improve immeasurably over time."

\section{The case for case finding}

Meanwhile, the much hyped app is still not ready, a month after the health and social care secretary, Matt Hancock, launched a trial on the Isle of Wight. This was supposed to automate much of the contact tracing by using Bluetooth technology to identify close contacts of an infected person. The government is now expected to make further announcements "in the coming weeks," says PHE.

However, the biggest problem with contact tracing in England is that "case finding" is currently not part of the government's plans, says Dominic Harrison, public health director at Blackburn with Darwen Borough Council. "If you just do contact tracing from the first symptomatic case-what we call the index case-you do get the vast majority of people infected, but you don't get them all," he says. "With case finding you take a different approach by saying, 'I'm going to test everybody potentially infected.' So, if you had one kid infected you might want to test the whole class or even the whole school."

Harrison insists that our ability to contain and suppress covid-19 hinges on putting case finding at the centre of the test and trace system. "If you look at the best contact tracing systems, they're doing case finding," he says, citing an example from South Korea, where an outbreak in a call centre in a tower block resulted in 1143 people being tested, of whom 97 were positive. ${ }^{6}$ Crucially, investigators identified asymptomatic carriers who would not have reported themselves under the English system.

\section{Local intelligence}

Scally emphasises the importance of building detailed local intelligence about outbreaks. "A particular concern has been the return to schools," he says. "That should be dependent on the level of infection in a locale, and there is no way at present to provide people with that knowledge. Case finding is the first step.

"At the moment we are reliant on a limited exhortation to people to get in touch if you've got symptoms and [to] come forward for testing. It should be a much more dynamic case finding: not just looking at that individual but looking back at where they may have infected themselves-a full investigation of each case.”

PHE emphasised that contacts are questioned closely to determine whether they are exhibiting any symptoms and appropriate follow-up action taken. Testing of asymptomatic contacts has been considered but is not part of the guidance at this time.

But England's ability to contain covid-19 will always be in doubt unless case finding is put at the heart of test and trace, says Harrison. "If we don't do case finding we are going to leave one or two or three cases in an outbreak undiscovered, and they will just keep the transmission chain going," he warns. "The risk is that, without case finding, the pandemic will have a very long tail and will never get to the endpoint. It will be around forever.”

In England the ability to carry out case finding is hampered in three ways: it's not part of the test and trace programme; government cuts to council funding have inflicted sharp reductions in public health staff such as health visitors, as well as environmental health 
and trading standards officers (who work with businesses); and local public health directors have no control over testing facilities.

Harrison adds, “There is no capacity for me to say, 'Here's a load of asymptomatic people from a workplace that I would like you to test."”

\section{Disproportionate impact}

This inability to direct testing resources is preventing public health teams from tackling one of the most insidious aspects of the pandemic in this country: the way it disproportionally hits deprived communities.

De Gruchy says, "We know it's the poorest and most vulnerable in society who are exposed. They are living in houses of multiple occupation. They might find it difficult to socially distance at work in low paid jobs. They would find it difficult to self-isolate and might have insecure employment."

Public health directors are therefore "alert to how any test and trace system widens health inequalities," she explains: they are pushing for contract tracers to check whether people who are asked to self-isolate are receiving or need local government support, such as with getting food or medicine.

Harrison says, "We know from the Office for National Statistics survey ${ }^{7}$ that, if you're in the wealthiest $10 \%$, you have half as many deaths as the poorest $10 \%$. So, there's two risks here. One is that we massively increase the inequalities-economic and social-for the lowest income groups or that, because they find it much more difficult to comply with that guidance, they will perhaps not comply.

'I'm paid monthly a good salary, so if I get told to isolate there's little cost to me. The guy that delivers pizza to my house, what's he going to do? That's a weakness in the whole system. If we get persistent levels of infection and transmission carrying on in certain postcode areas, or in certain occupational groups, we are never going to shut the virus down.”

Over the coming months several aspects of the test and trace programme will almost certainly improve. The contact tracers will become more proficient, the supply chain for testing kits will expand, the logistics for the Lighthouse Labs will speed up, and local public health teams will develop increasingly effective responses to local outbreaks. The app might even work.

But there's a long way to go. Johnson claimed that a "world beating" test and trace system would be in place by 1 June $^{8}$-but Harrison concludes, “It's clear we don't have the capacity to deliver a world beating system at the moment, and if we don't put a lot more resources in it's going to take a very long time to get there."

Competing interests: I have read and understood BMJ policy on declaration of interests and have no relevant interests to declare.

Provenance and peer review: Commissioned; not externally peer reviewed.

The Independent SAGE. https://www.independentsage.org.

2 Office for National Statistics. Coronavirus (COVID-19) Infection Survey pilot: 5 June 2020. 5 Jun 2020. https://www.ons.gov.uk/peoplepopulationandcommunity/healthandsocialcare/conditionsanddiseases/bulletins/coronaviruscovid19infectionsurveypilot/5june2020.

3 UK Lighthouse Labs Network. https://www. lighthouselabs.org.uk.

4 Smyth C. Coronavirus: Testing pledge does not include all cases. Times 2020 Jun 4. https://www.thetimes.co.uk/edition/news/boris-johnson-promises-faster-coronavirus-tests-asdeath-toll-passes-50-000-dtq23zlc7. (Subscription needed.)

5 Health and Social Care Committee. 3Jun 2020. https://parliamentlive.tv/Event/Index/7c6a6a33f653-4eff-8157-ab6bba7e63cb.

6 Park SY, Kim Y-M, Yi S, etal. Coronavirus disease outbreak in call center, South Korea. Emerg Infect Dis 2020;26. doi: 10.3201/eid2608.201274. pmid: 32324530
7 Office for National Statistics. Deaths involving COVID-19 by local area and socioeconomic deprivation: deaths occurring between 1 March and 17 April 2020. 1 May 2020. https://www.ons.gov.uk/peoplepopulationandcommunity/birthsdeathsandmarriages/deaths/bulletins/deathsinvolvingcovid19bylocalareasanddeprivation/deathsoccurringbetween1marchand17april.

8 Tolhurst A, Langford E. PMQs: Boris Johnson claims UK will have “world-beating” system to trace 10,000 coronavirus cases per day ready by 1 June. Politics Home 2020 May 20. https://www.politicshome.com/news/article/pm-claims-uk-will-have-worldbeating-test-trackand-trace-system-up-and-running-by-1-june.

9 Institute for Government. Joint Biosecurity Centre. https://www.instituteforgovernment.org.uk/explainers/joint-biosecurity-centre.

10 Woodcock A. Coronavirus: Chief medical officer Chris Whitty made decision not to lower UK alert level, No 10 says. Independent2020 Jun 3. https://www.independent.co.uk/news/uk/politics/coronavirus-uk-alert-level-cases-deaths-chris-whitty-latest-a9545051.html.

This article is made freely available for use in accordance with BMJ's website terms and conditions for the duration of the covid-19 pandemic or until otherwise determined by BMJ. You may use, download and print the article for any lawful, non-commercial purpose (including text and data mining) provided that all copyright notices and trade marks are retained. 